\title{
GANIVET Y SCHOPENHAUER: PENSADORES INTEMPESTIVOS
}

\author{
Ricardo DE LA FUENTE BALLESTEROS \\ Universidad de Valladolid
}

Un intempestivo es aquél que se enfrenta a las teorías, costumbres y modos de vivir contemporáneos. Es todo el que rechaza el pensamiento oficial y actúa con voluntad de independencia y denuncia. Nietzsche y Schopenhauer ${ }^{1}$ fueron dos filósofos intempestivos que dejaron una amplia muestra de sus desviaciones y que dieron ejemplo con su vida del alejamiento de sus contemporáneos desde la eminencia de su saber. Ganivet y Unamuno, entre otros fueron, entre nosotros, los escritores que más egregiamente levantaron su bandera de la disconformidad en el fin de siècle hispánico, partiendo, ambos, de principios aprendidos en estos filósofos alemanes. Uno de los muchos ejemplos que se pueden espigar del comportamiento de outsider del granadino - siempre a contrapelo, para traducir el título de otra cima del schopenhauerismo finisecular: $\grave{A}$ rebours de Huysmans- puede ser éste, entresacado de su rico y revelador Epistolario: "Creo que estóy en mi derecho sosteniendo la necesidad de sentir fuerte y groseramente contra la mayoría de los semejantes, reservando siempre a cada cual la facultad de sentir a su modo: el que sea débil, como tú crees que lo eres, se limitará a hablar, y el que se encuentre con gávilos puede ampliarse un poco y atizar duro, cuando sea posible.".

En este trabajo se tratará de mostrar las conexiones entre el filósofo de Dantzig y el autor de Granada la bella, si bien esta exposición no podrá pasar de ser un mero recorrido por la obra de Ganivet, una introducción a un tema que merece más reposados comentarios de una evidente influencia de la que se han hecho eco los

\footnotetext{
I Vid. J. Quesada (1988).

2 A. Ganivet, Obras Completas, II, Madrid, Aguilar, 1943, p. 907. [Todas las citas irán por esta edición y, como es lógico se obviará la nota].
} 
críticos que se han acercado con anterioridad a los textos de nuestro autor. Así Francés $^{3}$, Casalduero ${ }^{4}$, King Arjona ${ }^{5}$, Espina ${ }^{6}$, García Lorca ${ }^{7}$, Láscaris ${ }^{8}$, SantiáñezTió $^{\prime}$ y, en particular, Olmedo Moreno ${ }^{10}$, Herrero ${ }^{11}$, Fernández Almagro ${ }^{12}$ y Milszyn ${ }^{13}$. La mayoría de todos estos estudios y en particular de los tres últimos hacen hincapié en las conexiones del pensamiento ganivetiano con los principios relativos a la Voluntad, al dolor y a la estética, como señala Fernández Almagro: “„No fue Schopenhauer quien explicó el proceso liberatorio del conocimiento en orden a la voluntad, mediante esa contemplación pura y desinteresada que es toda la razón del arte? Ello es que la contemplación estética permite al hombre desintegrarse del mundo y gozarlo en la calma segura de la intuición." (135-136).

El conocimiento Schopenhauer por parte de Ganivet pudo ser a través de algunas de las tres traducciones ${ }^{14}$ que aparecen antes de su muerte: El Mundo como Voluntad y Representación de Antonio Zozaya y Edmundo González Blanco (18961902) ${ }^{15}$; pero la primera obra que se vierte al castellano es Aforismos sobre la sabiduria de la vida ${ }^{16}$ (1889) en versión de Zozaya. Otras obras en su primera traducción scrían las que a continuación detallo: las innominadas Estudios escogidos acerca de los Dolores del Mundo (1893) ${ }^{17}$ y El Fundamento de la Moral (1896) ${ }^{18}$. Con posterioridad a la muerte del escritor granadino las ediciones castellanas se

" J. Francés, “Epistolario, por Angel Ganivet”, La Lectura 3 (1904) 448-453.

$4 \quad$ J. Casaiduero, "Descripción del problema de la muerte en Angel Ganivet", Bulletin Hispanique 33 (1931) 214-246.

5 D. King Atjona, "La voluttad and abulia in Contemporary Spanish Ideology", Revue Hispanique 74 (1928) 573-671.

6 A. Espina. Ganivet. El hombre y la obra, Madrid; Espasa-Calpe, 1972.

7 F. García Lorca, Angel Ganivet. Su idea del hombre, Buenos Aires: Losada, 1952.

* C. Láscaris Comneno, "El pensamiento filosófico de Angel Ganivet", Revista de la Universidad de Buenos Aires 22 (1952) 453-533.

) N. Santíañez-Tió, Angel Ganivet, escritor modernista. Teoria y novela en el fin de siglo espanol, Madrid: Gredos, 1994; Idem, Angel Ganivet: una bibliografia anotada (1892-1995), Granada: Diputación de Granada, 1996.

10. M. Olmedo Moreno, El pensamiento de Ganivet, Madrid: Revista de Occidente, 1965.

1. J. Herrero, Angel Ganivet: un iluminado, Madrid: Gredos, 1966. Aquí se señala cómo el pensamiento de Ganivet y Schopenhauer están enlazados por una visión similar del hombre y de la vida (p. 71).

12. M. Fernández Almagro, Vida y obra de Angel Ganivet, Madrid: Revista de Occidente, 1952.

13. N. Milszyn, Laperspectiva filosófica y su proyección satírica en las novelas de Angel Ganivet, Ann Arbor: University Microfilms International, 1985.

is Para las ediciones en español de Schopenhauer vid. Arthur Hübscher: SchopenhalierBibliographie, Sttugart-Bad Cannstatt: Frommann-Holzboog, 1981, 89-93.

15 Madrid: La España Moderna, 1896-1902, 3 vols.

16. Madrid: José Rodríguez, 1889, 2 vols. Hay otras ediciones según se señala en la bibliografía final.

17 Madrid: Rodríguez Serra, 1893.

1. Madrid: la España Moderna, 1896. Más tarde la tradujo F. Díaz Crespo, Barcelona: F. Granada, 1906). 
multiplican: la unamuniana de Sobre la Voluntad en la Naturaleza (1900) $)^{19}$, Mefafísica de lo bello y Estética (1901) por Luis Jiménez García de Luna ${ }^{20}$, en este mismo año aparece La vida, el amor y la muerte firmada por Tomás Orts Ramos ${ }^{21}$, El amor; las mujeres y la muerte (1902) por A. López White ${ }^{22}$. Apuntes para la Historia de la Filosofía (1903) realizada por Luis Jiménez García de Luna ${ }^{23}$, La libertad (1903) por Roberto Robert ${ }^{24}$, Edmundo González Blanco tradujo La nigromancia en 19072., Estudios de Historia Filosófica (1908) por el mismo autor ${ }^{26}$ que, asimismo, también editó sin fecha la Eudemonología. Tratado de mundología o arte de bien vivir ${ }^{27}$ y Ensayos sobre Religión, Estética y Arqueología en 1908 ${ }^{28}$, La moral, la religión y la ciencia de la naturaleza (1908) por Francisco Lombardía ${ }^{20}$, Alrededor de la filosofía (1913) por este último autor ${ }^{30}$, Algunos ophisculos (1921) en versión de Fulgencio Ejea Abelenda. ${ }^{31}$, Las ciencias ocultas. Magnetismo animal. El destino del individuo. Ensayo sobre las apariciones de espíritus (1924) por J. Meliá ["Pigmalión] ]2, Los puntales de la dicha (1924) por E, Heras ${ }^{33}$, El amor, las mujeres y la muerte. Seguido de Máximas y Pensamientos (1929) por A. López White $3 . .$. Pero lo más lógico es que Ganivet conociese al alemán directamente en su lengua o a través de la versión francesa, pues en una de las numerosas citas explícitas que realiza, en la carta V (22-VII-1893) del Epistolario, se refiere al complemento del libro IV, cap. 44 de El Mundo como Voluntad y Representación, "Metafísica del amor". Es posible que hubiese manejado, como digo, la versión francesa ya que repite el error de esta traducción — que luego se dio en la castellana--: "Mctaphysik der Geschlechtsliebe", que correspondería más bien a "Metafísica de la sexualidad". Al hilo de un comentario de las obras de Tolstoi y Zola se refiere a éste como sigue: "La solución de Zola es pesimista, y filosóficamente

\footnotetext{
1.) Madrid: Rodriguez Serra, 1900.

2) Madrid: Rodriguez Serra, 1901.

2) Madrid: Rodríguez Serra, 1901.

22 Valencia: Sempere y Cía, 1902.

2.3 Madrid: Rodríguez Serra, 1903.

24 Valencia: F. Sempere y Cía., 1903. Hay otra traducción de E. Imaz, Madrid: revista de Occidente, 1934.

25. Madrid: La España Modema, 1907.

36. Madrid: La España Moderna, 1908.

27 Madrid: La España Moderna, s.a. En 1946 otra edición del mismo traductor con el título E/ are de biten vivir, Bucnos Aires: Ediciones Siglo XX, 1946.

2* Madrid: La España Moderna, 1908.

zy Madrid: La España Modema, 1908.

34) Valencia: Sempere y Cía, 1913.

3. Madrid: Reus, 1921.

32 Madrid: Aguilar, 1924.

3 Barcelona, s.i., 1924.

3 Barcelona: B, Bauzá, 1929.
} 
estaba ya dada en la Metafísica del amor, de Schopenhauer. Nosotros somos miserables siervos de la especie, a la cual servimos para proporcionarnos un placer engañoso y brutal" (O.C., II, 861). De todas formas, sabemos por su correspondencia que Ganivet estudió y el alemán y no sería extraño que su conocimiento de la filosofía schopenhaueriana fuese a través de las ediciones originales ${ }^{35}$. Lo que sí es cierto es que las citas sobre este pensador se pueden acumular, tanto en el Epistolario, como en textos fundamentales como el Idearium español ${ }^{36}$ (1896). Otra cuestión a tener en cuenta es cómo la filosofía de Schopenhauer se percibe nítidamente en los textos ganivetianos - particularmente en el Epistolario, El escultor de su alma y sus dos novelas: La conquista del reino de Maya y Los trabajos del infatigable creador Pío Cid - salvo en España filosófica contemporánea (1889).

Ganivet, como tantos otros escritores finiseculares, reacciona frente al positivismo, al materialismo y al evolucionismo. La crítica ganivetiana se centra en la despreocupación de estos sistemas de pensamiento por el hombre, su problemática y el alejamiento de lo espiritual. La obsesión por este tema lleva al granadino a crear a Pío Cid, que en La conquista del reino de Maya es un paradigma del pensamiento materialista ${ }^{37}$. Schopenhauer parte de la oposición kantiana entre fenómeno y noúmeno: espacio, tiempo y causalidad no son propiedades de la cosa en sí, independientemente de su representación en el sujeto sino que son las formas $a$ priori bajo las que se nos presenta el sujeto. El irracionalismo de Schopenhauer le lleva a plasmar lo óntico en la Voluntad de Vivir, especie de energeia que se mani-

35 Por otro, lado lado, la recepción de Schopenhauer se puede centrar en los años 70 del pasado siglo con personalidades como Emilio Huelin, José del Perojo, Leopoldo Alas, etc. Vid. a este respecto el artículo de Donald Santiago (1993).

3. "para el creyente, el drama será como un símbolo religioso, y los amantes no serán fuerzas ciegas movidas por el instinto, según la idea de Schopenhauer, sino dos almas dueñas de sus destinos ennobleciéndose por la abnegación y por la dignidad con que transforman la pasión humana, contraria al deber, en amor espiritual y místico, mediante la muerte por el dolor, la transfiguración, el tránsito desde la vida a las religiones donde el deber no existe, donde hay sólo un deber: el de amar, que más que deber es goce y deleite de las almas." (O.C., I, 214).

37 "Cada día me va siendo más difícil concretar mis ideas y fijar mi pensamiento sobre un objeto determinado. Tenía idea del misticismo positivo o efectivo de los místicos clásicos como tales, el cual consiste en una confusión de la personalidad con la idea general; hay en él anulación del sujeto como tal sujeto, pero no para desvanecerse, sino para exaltarse; lo que no conocía, y ahora he conocido, es un estado psicológico nuevo para mí, una especie de misticismo negativo producido por la repulsión contra la realidad. No se trata del nirvana ni de ninguna cosa por el estilo, sino de algo más sencillo y que se explica más fácilmente. El punto de partida, como el misticismo religioso, es el desprecio del mundo sensible, cl asco del espíritu por la materia; hablando en tono materialista, la incapacidad para asimilarse los elementos exteriores. En tal estado el espíritu se va y lo queda es se convierte en objeto, porque lo que nos constituye en sujetos es la facultad de representarnos el mundo exterior. Cuando el pensamiento no puede fijarse en nada concreto, ni quiere obedecer las órdenes de la voluntad, es evidente que nos quedamos tan convertidos en cosa como si fuésemos un espejo o una planta. Pero en le misticismo positivo el espíritu conserva aún un centro fundamental de la relaciones psíquicas; queda una función en vigor, la contemplación o la intuición de lo infinito; y bien puede decirse que nada se pierde en cl cambio, porque esta sola función abraza todas las ordinarias de la vida y ofrece de una vez lo que vanamente procuran las funciones particulares." (O.C., II, 823-824) 
fiesta en angustia y dolor en los sujetos en los que se objetiva. El mundo fenoménico, o realidad de apariencias esconde un núcleo irracional: la Voluntad de Vivir o energía cósmica que mueve a todos los seres en un afán de perpetuarse y autodevorarse. En el alemán este término siempre lleva mayúscula, para diferenciarlo de la voluntad individual que sólo sería uno de sus avatares. En el granadino aparece siempre con minúscula, quizás por un mayor énfasis en la voluntad individual a pesar del pesimismo que le lleva a reconocer que ésta no es sino un engaño. Así en el Epistolario leemos: "Realmente, lo único que hay, o que es, es la voluntad, la fuerza crcadora, cuya primera materia es el conocimiento y cuyo impulso es el sentimiento o lo que llamamos tal" (O.C., II, 843). "Todos los actos instintivos, fatales, aparecen encubiertos bajo ciertos disfraces, con los que voluntariamente nos engañamos para hacer como que obramos libremente, o por un estímulo libremente aceptado, cuando lo cierto es que somos maniquíes" (O.C., II, 1023) ${ }^{38}$. En la carta XII del 16 de septiembre de 1893, en la que da noticia de su obra La conquista del reino de Maya, hay una clara explicación de esta obra y del sometimiento de los principios racionales a la fuerza ciega externa que dirige el mundo. Aquí Ganivet no asume únicamente la teoría de Schopenhauer, sino que hace también referencias a otras posiciones filosóficas que postulan principios activos directores que se imponen al hombre -en particular los principios estoicos, que tan enfatizados han sido por la crítica- ${ }^{39}$.

Por otró lado, en Schopenhauer la Voluntad de Vivir tiene su máxima expresión en la sexualidad. Por ella, la especie busca su continuidad a expensas de los individuos que, atraídos por un placer pasajero, sacrificarán su propio bienestar y traicionarán sus principios racionales al reproducirse. Como dice el filosofo alemán, el acto sexual y lo que él conlleva es la evidencia de la "afirmación de la Voluntad de Vivir pura y sin mezcla" (El Mundo como Voluntad y Representación, IV, 60). La conceptualización de los sexos correspondiente a esta visión de la sexualidad hace de la mujer "la trampa" 40 que la especie tiende al hombre para perpetuar-

38 Ya en España filosófica contemporánea Ieemos, al igual que en Unamuno, su oposición sistemática frente a la razón, y en este caso oponiéndola a la fe: "Cuando la inteligencia se halla relativanente desenvuelta y dispuesta para apropiarse de las ideas; cuando el espíritu, virgen de toda duda, acepta las creencias con la fijeza propia de la Fe, y las conserva como depósito sagrado para el porvenir, en este momento fugaz de la vida del entendimiento debe comenzar la penosa y prudentísima labor de grabar en él clara y profundamente los principios de una religión y una filosofía. Es absurdo pretender que estas enseñanzas se reserven para cuando la razón, llegada a su madurez, pueda aceptar o rechazar según su propio discernimiento, pues en el mundo vivimos por la $\mathrm{Fe}$, sin la cual nuestra inteligencia no podrá dar sus primeros pasos ni aceptar ningún linaje de creencias. Aunque la razón pudiera perfeccionarse careciendo completanente de ella, ¿cómo prestaría jamás su asentimiento a ninguna idea en medio de las constantes controversias y de las eternas vacilaciones a que nos condena nuestra flaqueza intelectual, de las sombras que el escepticismo proyecta sobre todos los conocimientos humanos?" (O.C., II, 664).

39) Otra carta significativa es la XXI, del 4 de enero de 1895 , donde se vuelve a señalar el pesimismo de Ganivet y el engaño de la realidad fenoménica (O.C., II, 1028-1029).

4) Vid. Los trabajos del infatigable creador Pío Cid (O. C., II, 506-507). 
se. Criatura incapaz de elevarse a las cimas del pensamiento, la mujer ni siquicra es tan culpable como el varón en el acto de traer un nuevo ser a la cadena de dolor que es la vida.

La concepción ganivetiana de la mujer y de la sexualidad no llega a ser tan extrema, aunque se apoya en Schopenhauer y en las ideas que sobre ambos temas cran comunes en el ambiente intelectual europeo finisecular. La misoginia de Schopenhauer es reemplazada por el paternalismo hacia las mujeres. Puede señalarse alguna similitud con el tratamiento que esta cuestión tiene en Unamuno; así cl firme rechazo que el filósofo alemán tiene por la reproducción es sustituido por una mirada benévola sobre el matrimonio y la descendencia, vistos como un camino apropiado para quienes no alcanzan la santidad por la vía del ascetismo. Así, en el Epistolario se nos manifiestan los intereses de la especie, pues la astucia de la Voluntad de Vivir se disfraza de motivos personales: "Con el tiempo llega uno a convencerse que está de más en el mundo; que no hay fines propios del hombre, porque los únicos fines (que son la generación y conservación) son fines específicos no individuales, que no hace uno nada esencial, o si hace algo es engendrar otro ser análogo o peor, y que todas las demás ocupaciones son formales o imitativas y como eflorescencias que produce el roce orgánico" (O.C., II, 1028-1029). Un poco más adelante incide en el tema de la trampa de la especie: "Dígase lo que se quicra, todo requiere un fin en el mundo, y el gran desencanto llega cuando en cl fin más alto se descubre el vacío. Un amor sin objeto es muy bonito, pero muy poco consistente; un amor con objeto es más prosaico, más duradero y embrutecedor en demasía; porque ese objeto es la cría de los hijos, en los cuales no sólo está la finalidad del padre, sino que tampoco puede estar la suya propia. Así, todo lo que el hombre crea tiene fines aparentes que se alejan como el horizonte visible; cl horizonte está en los ojos y no en la realidad, y nuestro fin, que es cooperar a una obra inacabable, aunque tenga un valor real, es inapreciable y hasta digno de desprecio." (O. C., II, 1030) Concluye que el estado natural es el de la "fornicación permanente" (O.C., II, 1031), donde a la temática schopenhaueriana de la sexualidad como manifestación pura de la Voluntad de Vivir se agrega aquí una consideración muy de época sobre la decadencia de la civilización y la peligrosa superioridad de lo primitivo. Esto es lo que intentará mostrar, precisamente, en su novela La conquista del reino de Maya: Pío Cid en esta sociedad se dedica a romper con los modelos de su sociedad, dedicado a los goces de la poligamia, convertido en ejemplo de la fuerza avasalladora de la Voluntad.

En relación con el tema de la mujer y de la sexualidad son muchos los aspectos que conectan el discurso de Ganivet y de Schopenhauer. Así, por ejemplo, en Los trabajos del infatigable creador Pio Cid se defienden los impulsos de la especie y los derechos de la sangre y de la naturaleza frente a los matrimonios de conveniencia, en el diálogo entre la duquesa y el protagonista (O.C. , II, 561-563). Schopenhauer en su Metafísica de la sexualidad opone el matrimonio de razón y el 
de amor, paradigmas de Civilización y Naturaleza, y si bien afirma que ninguno de los dos alcanza la felicidad, prefiere el de la Naturaleza, pues este último es más afín a la Idea de la especie y es el sojuzgamiento a los dictámenes trágicos de la Voluntad. Por otro lado, el verdadero destino de la mujer es la maternidad ${ }^{41}$ y el amor es el único medio de elevación espiritual de ésta ${ }^{42}$. Como Unamuno, para Ganivet la mujer es una especie de tierra nutricia y el hombre es un árbol que protege y fecunda: "Una mujer debe ser como la tierra, y un hombre como un árbol; una tierra sin árboles se convierte en un arenal infecundo, y un árbol sin tierra muere porque se secan sus raíces; la vida que la tierra le da al árbol, el árbol se la devuelve con su sombra protectora. Así la mujer mantiene al hombre ligado a la realidad, para que no se aparte de ella ni se pierda en estériles idealismos, y el hombre, en cambio, protege a la mujer con la sombra de sus ideas para que no se aniquile como se aniquilaría dejándola sola, a merced del viento, de los caprichos fugaces" (O.C. II, 550-551). Estas últimas opiniones son, evidentes divergencias de los planteamientos de Schopenhauer. Hay, por ejemplo, una apología de la familia pobre y numerosa en Los trabajos..., en lógica oposición, también, al positivismo y al malthusianismo, formas de la razón calculadora y burguesa, y probablemente derivada de los presupuestos católicos.

Otro aspecto que se debe comentar básico del pensamiento de Schopenhauer es la negación del progreso histórico, frente a las opiniones oficiales que ejercían el optimismo hegeliano o positivo. La Historia es mero fenómeno, sucesión de individuos que no mejoran el destino humano ni tienen una finalidad (El Mundo como Voluntad y Representación, III, 35). Estas ideas, además de puestas en práctica con fines satíricos en La conquista..., se pueden extrapolar en el Epistolario y, en particular, en la carta XXX, donde explícitamente se afirma que la Humanidad no se puede reformar, y que al hombre inteligente sólo le queda el lema de la ética individualista estoica "abstine et sustine" (abstente de gozar y soporta el dolor: la vida es una lucha contra las pasiones para evitar el dolor que produce ser dominado por ellas. $)^{43}$.

La fïlosofía de Schopenhauer ha sido considerada una filosofía de la tragedia $^{44}$ ya que el comienzo del filosofar se produce con el descubrimiento del dolor universal. Como en las tragedias, el final de las vidas es siempre fatal y poco pue-

$4 i$ "No hay para la mujer refugio más seguro que el amor maternal" (O.C., II, 560).

42 "...] porque para la mujer no hay otro medio de penetrar en las cosas que simbolizarlas en el hombre amado." "Hay algo más grande; pero para llegar a ello no hay más camino que el amor. El mejor amor es el espiritual, y si éste no basta, el amor corpóreo. Hay semillas que sólo germinan en hoyas muy abrigadas, y casi todos los hombres son semillas así." (O.C., Il, 552)

4.3 Vid. O.C., II, p. 1026.

4t Vid. Philonenko (1989). 
den hacer los protagonistas frente al destino $0^{45}$. Este planteamiento desemboca en el nihilismo, pues el sufrimiento es absurdo ya que no existe finalidad trascendente alguna. Este sentido de la vida como absurdo es expresado en varias ocasiones por Ganivet, como en la carta XXX: "Y creyendo yo, como creo, que no tenemos ningún fin que cumplir, ¿cómo me atribuyes tú eso de que lo que se hace sea obra de la voluntad y de la reflexión y no de la naturaleza? Yo estoy convencido de que se debe hacer lo que buenamente salga; pero estoy más convencido de que salga Io que saliere no sirve para realizar ningún fin particular nuestro; de que vivimos atados a la noria, unas veces para dar vueltas en tonto, porque la noria está seca, y otras para sacar agua, sin saber si sale o no, porque tenemos los ojos vendados para evitar el mareo" (O.C., II, 1024). También el concepto de destino es reflejado nítidamente por el granadino: "Pío Cid partió contento, porque en estos cambios decididos por el azar, y a los que él nunca se opuso, creía ver la acción de una fuerza misteriosa que rige la vida de los hombres, encaminándoles hacia sus verdaderos destinos" (O. C., II, 582) ${ }^{46}$.

En Schopenhauer la tiranía del principio de individuación nos impide ver la unidad profunda de la realidad, por debajo de su multiplicidad fenoménica. Pero diversas vías de acceso al conocimiento de la esencia metafísica se abren: una es provisional y pasajera, contemplación estética que por un momento nos distrae de la sumisión a las pasiones e intereses personales. Se produce con ella la suspensión de la cadena del deseo (Maya) y la entrada en un ámbito no sometido a los límites del espacio y del tiempo, propios de la realidad fenoménica ${ }^{47}$. Para Ganivet las pasiones dominan al hombre, lo esclavizan, lo atan a lo material, las pasiones son "insaciables", el hombre está dominado por el deseo de poder, de posesión, por la ambición y por la necesidad de satisfacer sus necesidades orgánicas ${ }^{48}$. En El escultor de su alma lo dice paladinamente: "iDesprecia ese cuerpo inerte, / que es el nido de tu muerte! / Ese es el caos, donde yace / la luz que en tu muerte nace..." (O.C., II, 743). Como si de un platónico o pitagórico se tratase se nos habla aquí de

45 La idea del destino está tratada en clave esotérica en el opúsculo Especulación trascendente sobre los visos de intencionalidad en el Destino del Individuo que formaba parte de los Parerga y Paralipómena [A. Schopenhauer, Los designios del destino (Madrid: Tecnos, 1994) Estudio preliminar, traducción y notas de Roberto Rodríguez Aramayo].

46 Vid. también O.C., II, 70.

47 La contemplación estética implica el abandono del principio de razón. De esta manera se marca "la diferencia entre un conocimiento de lo óntico (o conocimiento utilitario) y un conocimiento ontológico (o conocimiento de la esencia)" en A. H. Puleo (60) y Philonenko (123).

48 Entre esta dominación de los instintos, como manifestación de Voluntad, se encuentra la crueldad gratuita, el regocijo ante la contemplación del sufrimiento ajeno. En La conquista Ganivet, además de mostrarnos el espectáculo de la Voluntad desatada en el pueblo Maya, explica la necesidad irrevocable de la guerra como sigue: "la verdadera civilización exige imperiosamente, ya que no sea posible extinguir los odios entre los hombres, ir agrandando cada vez más las filas de combate hasta llegar a destruir los odios parciales y congregar a todos los hombres en dos masas enemigas, que, o bien se destruyen recíprocamente y definitivamente, o bien se decidan a vivir en paz a causa del miedo mutuo permanente." (O. C., I, 574) 
la cárcel del cuerpo y Ganivet se nos muestra con el deseo ascensional de quien desea liberarse de las cadenas de la humana condición, para llegar al punto culminante de la contemplación, que es una de las obsesiones ganivetianas. La contemplación es tan importante que se opone a la actividad -otro de los conceptos claves de su pensamiento- Como señala Herrero: "Esta superioridad de la contemplación sobre la vida activa es esencial al hombre; es decir, la más alta operación del alma humana es la visión del mundo ideal y, especialmente, la contemplación del Amor Supremo, del Artífice. La vida activa se justifica solamente cuando persigue la realización de algún ideal" (Herrero 1966, 17).

La contemplación, lógicamente, sólo puede venir merced a la potenciación de lo interior, es decir, de la fuente del noúmeno. Y una de las maneras para acceder a la visión de las esencias es la vía estética. Así, las poesías que jalonan el texto de Los trabajos constituyen formas de eludir el destino y las necesidades contingentes -por ejemplo el último de los poemas de despedida a la duquesa-. Placer estético, desprecio por la sociedad moderna y espiritualidad cristiana se funden en la atracción de Pío Cid por los cánticos de las monjas ${ }^{49}$.

En Schopenhauer existe una jerarquía de perfección ética que muestra diversos grados de liberación individual frente al egoísmo propio de la Voluntad de Vivir: 1) ser justo; 2) ser benevolente; 3 ) ser santo (negación total de la Voluntad por el ascetismo). Como puede percibirse por esta jerarquización, la moral kantiana del deber y la justicia es considerada inferior a la de la compasión, inspirada por los sentimientos y por la comprensión del principio védico "tat twan asi" ("eso eres tú"), todos los seres vivos son Voluntad de Vivir y participan del sufrimiento y en eso se igualan ${ }^{50}$. Pío Cid en Los trabajos es el paradigma del hombre contemplativo, del asceta, del héroe finisecular que nos propone Ganivet - casto, resignado, austero y que acepta su propia finitud-_.5. Así, se afirma que la contemplación es lo único que nos diferencia del hombre primitivo: "la facultad de contemplar es quizá la única que nos diferencia del hombre primitivo y salvaje, que, por no saber contemplar las cosas, no descubre las relaciones espirituales que hay entre ellas y el hombre, y se limita a expresar sensaciones materiales por medio de unas cuantas palabras indispensables para la vida

4) "Me gusta pasar por las cercanías de los conventos de monjas a la hora de los maitines o vísperas, cuando llega a mi oído el vago rumor de las canciones, que me suenan a cosa inmutable y perenne como los movimientos de los astros. Para esta inquietud malsana que devora hoy a los hombres no hay mejor medicina que esos cánticos, que antes eran himnos de la fe, y ahora, por el cambio de los tiempos, son himnos de desprecio a esta sociedad, cuya gloria se cifra en agitarse sin motivo y sin objeto" (O. C., II, 226-227).

50 En Schopenhauer este concepto está ligado con la Gracia cristiana, pues a la compasión se llega no por la razón. Por otro lado, su propuesta ética la reconoce unida a las propuestas del cristianisno primitivo según lo recogió Lutero (El Mundo como Voluntad y Representación, IV, 70). Vid. Puleo (74).

51 Sobre el héroe schopenhaueriano léanse las atinadas páginas de P. Gardiner (1975, 425-451).

52 Vid. la explicación de Herrero (281-283). 
corporal. [...]. Lo que nosotros percibimos por la contemplación es para el salvaje tan confuso, como lo es para nosotros la armonía universal, que sospechamos que nos envuelve como melodía inefable, engendrada por el movimiento concertado de los átomos, pero que no podemos gozar porque nuestros sentidos son demasiado groseros para percibir tan sutiles sublimidades." (O.C., II, 217-218). Este personaje se muestra despojado de interés por la fama, por el dinero, por las cuestiones materiales, semejando una especie de sacerdote seglar que aspira únicamente a ser un hombre, no una simple representación (fenómeno): "hay quien coloca el centro de la vida humana en el poder exterior, en la riqueza, en un bien convencional. Yo pongo el centro en el espíritu. ¿Qué soy? Nada. ¿Qué apetezco? Nada. ¿Qué represento? Nada. ¿Qué poseo? Nada. Ahora estoy en camino de ser un verdadero hombre, puesto que si existe mi personalidad sin buscar apoyo fuera de sí, es porque dentro tiene su fuerza" (O. C., II, 447). Aquí, en la fuente del Avellano, Pío/Ganivet predica la necesidad de la contemplación del ideal y el abandono de las luchas materiales. Todo ello centrado en el famoso poema "Ecce homo" que representa la vida del hombre y el impulso de éste hacia la Belleza ideal y hacia la muerte liberadora ${ }^{52}$.

En Ganivet, el ágape, el amor puro o compasión está representado por el Pío Cid de Los trabajos..., que compadece a los seres marcados por un destino adverso - caso de Mercedes - y que se admira ante el ideal monástico - O. C., II, pp. 220 y 226-228-. En La conquista..., por el contrario, la sumisión a las pasiones y deseos, la falta de compasión, clave de los descubrimientos metafísicos, impiden la liberación de las redes de Maya, la ilusión fenoménica ${ }^{53}$.

Al igual que en Unamuno, para el que el dolor es lo que hace sumergirse al individuo en el hondón del alma, mostrándole la cara verdadera de la existencia, la nouménica, frente a las múltiples facetas del fenómeno, en Ganivet, este dolor va a ser un elemento fundamental del conocimiento, dentro de la perspectiva schopenhaueriana. Para el granadino la vida es dolor, pero que implica saber: "ese vulgo no conoce porque no quiere llegar al goce por el dolor, ni siquiera por el dolor teatral, fingido, puesto que ya ve usted que la tragedia y el drama van de capa caída y que el público lo que desea es reír mecánica y tontamente. ¡Pobre gentecilla, que ignora que el sufrimiento llena la mayor parte de la vida, y que huye de la vida por huir del sufrimiento, y se contenta con hacer una alegre digestión de lo bueno o malo que come!" (O. C., II, 258) ${ }^{54}$.

Según Schopenhauer el suicidio no puede ser vía de liberación ya que la Voluntad de Vivir no se extingue con un acto tan violento que en realidad expresa el deseo de vivir de otra manera (El Mundo como Voluntad y Representación IV, 68 y 70), no la decisión de abolir todo deseo (doctrina hindú sobre la necesidad de

53 Vid. O.C., II, 24, 99, 449-450.

54 Vid. también O. C., II, 561. 
extinguir la vida como se seca una planta para impedir que rebrote en las sucesivas reencarnaciones). La Voluntad sólo se puede superar por medio del ascetismo, de la llamada "santidad".

Ganivet asume esta teoría de Schopenhauer sin alteración alguna, a pesar de contener la controvertida hipótesis de la metempsícosis o palingenesia. Así, podemos leer en la carta XXXI: "En ambos casos [ser útil o inútil] puedo permitirme la satisfacción de entretenerme con mis imaginaciones para disfrazar las miserias de la vida e impedir que se acerque la idea del suicidio, que no resuelve nada tampoco si, como es de temer, tenemos varias ediciones, y cuanto antes nos inutilizamos tanto antes nos echan tapas y medias suelas en el laboratorio de las almas para lanzarnos a funcionar de nuevo en este planeta o en otro, si hay varios que nos ayuden en estas faenas" (O.C., II, 1031).

La presencia de Schopenhauer en Ganivet es una evidencia, y este trabajo no descubre en este sentido ninguna tierra ignota, si bien es llamativa la penetración de los principios de este filósofo en la escritura del desafortunado suicida de Riga. Las cartas muestran a las claras la permeabilidad del texto a la elegancia y originalidad de las ideas del maestro alemán, y aunque en las novelas podamos encontrar otros matices, además de los propiamente schopenhauerianos —en particular Hegel y Nietzsche-, lo evidente es que la interpretación schopenhaueriana se afirma sobre las demás. La aporía creación / destrucción, en clave de manifestación de la Voluntad ciega, y en clara consonancia con los modelos darwinistas y spencerianos alumbraría en La conquista del reino Maya, mientras que Los trabajos del infatigable creador Pío Cid, como ya se ha señalado, es la apuesta por la transformación del protagonista de la novela anterior en un asceta que parece escapar de Maya y se convierte en el hombre compasivo, capaz sólo de amar y comprender cordialmente a los demás sujetos, que, como él, están sujetos al inexorable dolor de la vida y de su aniquilamiento: "El único sentimiento que yo soy capaz de sentir es el amor, y lo siento por cuantas personas conozco" (O.C., II, 209).

\section{BIBLIOGRAFÍA CITADA}

FERNÁNDEZ ALMAGRO, M. 1952. Vida y obra de Ángel Ganivet, Madrid, Revista de Occidente.

GARDINER, P. 1975. Schopenhauer, México, Fondo de Cultura Económica.

HERRERO, J. 1966. Ángel Ganivet: un iluminado, Madrid, Gredos.

PHILONENKO, A. 1989. Schopenhauer. Una filosofía de la tragedia, Barcelona, Anthropos. 
PULEO, Alicia H. 1991. Cómo leer a Schopenhauer, Madrid, Júcar.

QUESADA, J. 1988. "Lectura nietzscheana de El mundo como voluntad y representación: Schopenhauer como antecedente", en Un pensamiento intempestivo. Ontología, estética y política en F. Nietzsche, prol. de J. M. Cordón, Barcelona, Anthropos.

SANTIAGO, Donald. 1993. "La recepción de Schopenhauer en España", Anthropos (Documentos A), $n^{\circ}$ 6, págs. 146-155. 